Francisco de Assis Toledo, professor da Faculdade de Direito do Distrito Federal CEUB, é subprocurador geral da República junto ao Supremo Tribunal Federal.

\title{
Aspectos gerais da reforma penal brasileira
}

1. Em julho de 1980, logo no início dos trabaIhos da primeira comissão de reforma - a de processo penal - tomamos a iniciativa de, através do Dr. Laércio Pellegrino, propor ao Instituto dos Advogados Brasileiros fossem abertos aqui, sob os auspícios desta tradicional instituição, os debates públicos em torno da reforma projetada. $E$ isso de fato se fez, conforme está registrado nos anais desta casa e na apresentação do ministro da Justiça ao Anteprojeto de Código de Processo Penal de 1981. Lembro-me de que, na mesma ocasião, tomava posse, como membro efetivo do Instituto, um dos mais operosos partícipes das comissões reformadoras, o professor Rogério Lauria Tucci. No dia seguinte, outra concorrida reunião de debates realizava-se no Conselho Federal da Ordem dos Advogados do Brasil. E assim começava a ganhar corpo, publicamente, o mais recente movimento de reforma do sistema penal e processual penal brasileiro, com três anteprojetos de lei publicados, amplamente debatidos em todo o país, e com os respectivos projetos definitivos elaborados, com acolhimento de inúmeras críticas, e já entregues às autoridades" governamentais.

Não foi por mero acaso a escolha desta casa para o início dos debates sobre a reforma. Advertidos pelo adágio segundo o qual ex nihilo nihil, ou seja, do nada nada se extrai, animou-nos o pensamento de que deveríamos procurar um lugar como este, repositório de tradições e de cultura, onde desde o Império se reúnem as figuras mais expressivas de nossa cultura jurídica, sem distinção de escolas ou de procedência, e, principalmente, onde o espírito generoso dos advogados nunca regateou quan- do se trata de trabalhar para o aperfeiçoamento de nossas instituições. Em um lugar como este - frisese - ser-nos-ia fácil encontrar a colaboração desinteressada e o alento para empreender a tarefa, quase impossivel, de unir, em um amplo projeto de reforma, o velho ao novo, o passado ao presente, o presente ao futuro.

Não erramos na escolha. Os fatos supervenientes o atestam. Por isso é que, de novo - e com o ânimo de quem ainda se propõe a discutir o que se fez - comparecemos a este auditório para dizer alguma coisa sobre alguns aspectos da reforma projetada, dada a impossibilidade física de examiná-la detalhadamente em uma única conferência.

A crise da justiça criminal brasileira e de nossos presídios resulta, ao que tudo indica, de um complexo de fatores. Não seria correto, pois, procurar-se atribuir a uma causa única todos os problemas que nos afligem nessa área. A carência de maiores recursos materiais, a falta de especialização dos magistrados designados para as varas e câmaras criminais, o número insuficiente deles, a falta de continuidade na edificação de novos estabelecimentos penais, o despreparo dos servidores e agentes lotados nesses estabelecimentos, tudo isso, é certo, não poderia deixar de ser computado, com outros fatores, em qualquer levantamento que se fizesse sobre as origens da crise inicialmente referida. Todavia, parece igualmente certo que se pretendéssemos suprir essas falhas só com o emprego de novos e maiores recursos financeiros no aperfeiçoamento daqueles órgãos, sem uma significativa mudança nos rumos da política criminal que informa o 
conjunto da legislação penal e processual penal editada nos anos 1940, entraríamos em um beco sem saída. É que, nesse caso, dentro de um sistema de caráter nitidamente repressivo, com a pena de prisão profusamente cominada, até para fatos insignificantes, a exigência de maiores recursos para a edificação de presídios, penitenciárias e para a respectiva manutenção cresceria numa diabólica progressão geométrica em relação à multiplicação de novas condenações proferidas por uma justiça ampliada, melhor aparelhada, mais rápida e mais eficiente. Isso só não aconteceria, dentro dessa perspectiva, se a pena de prisão deixasse de ser executada, ficando como letra morta no papel, ou se o Estado se dispusesse a desviar recursos substanciais de outros setores para a construção de estabelecimentos penais.

Assim, aos que pretendem ver solucionado o problema criminal brasileiro com o só reaparelhamento dos órgãos da repressão penal, seguido da construção de novos estabelecimentos de segregação social de acusados e de condenados, poderíamos endereçar a seguinte observação: preparem-se, então, para transformar as condenações penais em pura ficção, em letra morta no papel, em algo não muito sério, ou seja, sentenças inexeqüíveis, como já vem ocorrendo em certas capitais, com grande número delas, ou - o que seria pior - preparemse para transferir recursos, muito importantes e expressivos, das áreas de habitação, saúde, saneamento, educação, transportes etc. , para a construção de um número cada vez maior de cadeias públicas e de penitenciárias, num círculo vicioso interminável e insuperável.

Será isso o que deseja a sociedade brasileira? A resposta afigura-se-nos evidentemente negativa.

Essas considerações, de ordem prática, que, por si sós, já conduziriam a se ter que repensar o sistema vigente do direito criminal brasileiro, não são, porém, as únicas nem as mais importantes. Estas -as mais importantes - situam-se em um plano histórico irreversível, do qual não poderão fugir os países do mundo democrático e civilizado. Refiro-me ao curso ascendente do movimento internacional de reforma do direito penal que, no dizer de Jescheck, desenvolve-se presentemente de modo tão intenso que não encontra símile na história, visto como tal movimento "constitui um signo da mudança espiritual que se produziu, a partir da metade deste século, na atitude frente a criminalidade e diante das possibilidades e métodos para combatê-la". 2

Note-se que não se trata de um movimento romântico, utópico ou panfletário, pois já produziu importantes efeitos. A Organização das Nações Unidas - ONU - , em documento que fez circular no último Congresso de Caracas, registrou, textualmen- te, experiências significativas de várias nações, a saber: "... Na maior parte dos casos [refere-se o documento às mais recentes reformas legislativas], a nova legislação prevê penas não privativas da liberdade (medidas diferentes da reclusão). Em vários países, em $90 \%$ ou mais de todas as sentenças proferidas pelos tribunais, impuseram-se multas baseadas nas rendas ou no patrimônio do delinqüente. Em um número cada vez maior de países estão sendo aplicados sistemas de indenização ou de compensação em favor das vítimas. A liberdade vigiada, a suspensão de sentenças, a prestação de serviços à comunidade, por ordem judicial, e outras soluções estão contribuindo para reduzir a reclusão, especialmente no caso do delinqüente primário. Na Romênia, por exemplo, depois da promulgação da nova lei de 1977, segundo a qual as penas de reclusão até cinco anos podem ser substituídas por penas de trabalho, sem privação da liberdade, a proporção de condenados à reclusão caiu de $66 \%$, em 1976, para $29,4 \%$, em 1979. Na Austria, a porcentagem de condenações à reclusão diminui de 40\%, em 1971, para $23 \%$ de todas as sentenças, em 1977. No Japão, em 1977, a proporção de penas de prisão era de $5,9 \%$, ao passo que as de outra índole (não privativas da liberdade) atingiam a cifra de $97,1 \%$. Na Inglaterra, um relatório do conselho consultivo sobre reforma penal inclinou-se para redução da duração das penas de prisão em favor das condenações de breve e média duração, tendo em vista que isso não desprezaria o efeito suasório da reclusão. Uma atitude similar foi adotada na Suécia e na Finlândia, cujo comitê de peritos sobre reforma penal concluiu que quanto mais enérgicas eram as medidas da sociedade contra o delinqüente tanto maiores erąm as probabilidades de reincidência, no futuro"...

No Brasil, esse movimento está presente e já tem aflorado em inúmeras ocasiões, deixando marcas indeléveis de uma firme tendência evolutiva, o que se constata, por exemplo, com as moções de Goiânia de setembro de 1973 e de junho de 1981, com as conclusões da CPI da situação penitenciária, de 1976, com a tentativa frustrada de edição de um novo código em 1969, com a edição da lei 6416 , de 1977, e com as inúmeras e freqüentes manifestações reformistas por parte dos mais expressivos penalistas pátrios. Não é possível, pois, a essa altu$\mathrm{ra}$, retardar por mais tempo a reforma do ordenamento jurídico penal brasileiro.

Por outro lado, parece também correto dizerse que, presentemente, com o desenvolvimento das pesquisas criminológicas e sociológicas, só uma imperdoável ingenuidade poderia levar a supor que o controle do fenômeno do crime possa ser levado a bom termo com o emprego exclusivo de clássicas medidas de ordem jurídico-repressivas. Não obstan- 
te, só uma outra ingenuidade ainda maior poderá igualmente conduzir à crença de que, em algum lugar, algum dia, será possivel abolirem-se aqueles instrumentos jurídicos, por que se terá atingido o ideal - se é que isso possa ser considerado um verdadeiro ideal - de uma sociedade composta só de homens e mulheres bem comportados, espécies de autômatos ou de robôs sobrevivendo em um 'admirável mundo novo'.

2. Postos esses limites extremos, mais ou menos evidentes, e feita abstração de detalhes, construiu-se, nos últimos tempos, um pensamento bastante simples, que assim se poderia enunciar: a) as medidas de controle do fenômeno do crime não podem ser exclusivamente jurídicas, devendo situarse dentro de uma estratégia global de prevenção que envolva também - e principalmente - medidas de caráter extrapenal, sem excluir, é claro, as de caráter penal, reputadas indispensáveis como última razão do Estado; ${ }^{4}$ b) os órgãos da repressão penal (polícia, ministério público e justiça criminal) devem concentrar sua atividade preferentemente sobre a criminalidade mais grave, deixando os fatos de pequena monta para procedimentos sumários, com previsão de imposicão de sanções diferentes da pena de prisão, dando-se ênfase às penas pecuniárias, restritivas de direitos e a outras semelhantes (assim Jescheck, op. eloc. cit.); c) a prevenção, e não a repressão, deve ser o objetivo mais importante a ser alcançado, dentro daquela estratégia global.

A partir desse pensamento, que, como se vê, é extremamente simples e claro, quase cartesiano, poder-se-á deduzir todo um sistema inteiramente novo e diverso daquele que se edificou sobre a crença exagerada nas virtudes da pena de prisão e no poder de intimidação ou de regeneração do cárcere, da pena como penitência - crença esta hoje em dia em franco declínio, se é que ainda existe.

Confinando-se, assim, o sistema criminal dentro de um conjunto mais amplo de medidas de controle da criminalidade, chega-se, sem muito esforço, a uma concepção simples e pragmática do referido sistema e também do objetivo que se busca alcançar com a reforma projetada, seacolhidos forem os projetos tal como elaborados pelas três comissões revisoras: um sistema criminal do direito brasileiro, que não pretenda inutilmente ser panacéia ineficaz para todos os males e dificuldades de nossa sociedade; que não pretenda, em razão disso, ser o único instrumento de controle e contenção da criminalidade, que, por outro lado, não se mostre omisso e ineficiente quando o interesse social e da segurança da paz pública e do individuo esteja a exigir a segregação e o confinamento de perigosos delinqüentes, por terem falhado os demais métodos de controle ou de reação extrapenais; que finalmente, apesar de tudo, procure humanizar de modo efetivo, e não puramente retórico, a execução das penas criminais, notadamente a de privação da liberdade sempre que esta não puder ser substituída por outras formas de sanção.

Como atingir-se tal objetivo? Dada a limitação do tempo de que dispomos, recorreremos a alguns poucos exemplos.

3. Previu-se a criação do Conselho Nacional de Política Criminal e Penitenciária. Esse órgão, que deverá ser integrado, segundo se espera, por especialistas de notável saber a experiência, nomeados pelo presidente da República, terá a incumbência de elaborar as diretrizes de um política criminal e penitenciária a ser observada em todo o país, guardadas as peculiaridades regionais. Será um órgão normativo e de fiscalização, cabendo-lhe, ainda, contribuir de modo direto e efetivo para a implementação das determinações e recomendações que fizer, com vistas à realização dos fins da reforma penal e penitenciária.

Pretende-se, com a criação desse conselho, retirar do empirismo em que se encontra, no Brasil, a formulação de critérios diretivos no âmbito da prevencão e repressão do crime e na esfera da organizacão penitenciária, evitando-se soluções de continuidade, contradicões e os conhecimentos altos e baixos. Preservou-se, contudo, a autonomia das unidades federativas, atuando o conselho precipuamente na faixa reservada à esfera de atribuições dos órgãos da União.

Em suma, o referido conselho irá contribuir, como tarefa fundamental, para a elaboração, por parte do governo, de um plano amplo e bem coordenado de controle do fenômeno da criminalidade.

4. Na área processual, entre outras muitas inovações previu-se a criação de juizados especiais com competência privativa para julgamento, em procedimento sumaríssimo, puramente oral, dos crimes punidoș com detenção até um ano, das contravenç̃es penais e dos crimes de homicídio culposo e de lesão corporal culposa, qualquer que seja a pena. Paralelamente previu-se a criação de órgão colegiado de primeira instância para julgamento dos recursos interpostos naqueles processos. Tais propostas já constavam do Anteprojeto publicado pela Imprensa Nacional em 1981. São providências que, a nosso ver, significarão uma completa reformulação da justiça criminal de primeira instância e permitirão com a dispensa do inquérito policial, no referido procedimento sumaríssimo, alcançarem-se, a um só tempo, as seguintes metas: a) desafogar as atuais varas criminais que, com a descentralização da grande massa de causas de menor importância, poderão concentrar sua atividade sobre os processos re- 
lativos aos crimes mais graves e aos delinqüentes mais perigosos; b) desafogar desses mesmos processos os tribunais; c) liberar as delegacias de policia de uma apreciável sobrecarga de trabalho que, a partir da reforma, será realizada, de modo mais simples, diretamente pelos promotores e juizes, nos denominados juizados especiais; d) aproximar a justica criminal dos seus jurisdicionados, de sorte que as lides de menor importância possam ser decididas de maneira rápida, próxima ao local do fato e com o devido senso de justiça e eqüidade.

Note-se que, na redação do projeto definitivo, assegurou-se no mencionado procedimento sumaríssimo ampla defesa aos acusados, através de advogado constituído ou dativo, dentro da melhor tradição do direito brasileiro. E ensejaram-se os prazos necessários para que essa ampla defesa possa realmente desenvolver-se.

Com isso, espera-se que a polícia, o ministério público e a justiça criminal possam concentrarse, de modo mais eficiente, sobre a criminalidade mais grave, deixando os fatos de pequena monta para os juizados especiais que, nos grandes centros urbanos, poderão funcionar em regime de plantão, se necessário, e caso assim disponha a respectiva legislação de organização judiciária.

É uma experiência digna de ser tentada, pela primeira vez, no Brasil. Acredito, sinceramente, que, com as cautelas e com a prudência com que tais inovações foram projetadas, dessa tentativa só poderão resultar benefícios, nunca resultados piores do que aqueles que nos têm sido oferecidos pelo antiquado sistema vigente

5. É claro que as inovações do projeto de Código de processo penal e do da Lei de execucão penal não se limitam aos aspectos antes citados exemplificativamente. São muito mais extensas e profundas, conforme tiveram oportunidade de revelar aos ouvintes os inúmeros expositores que me precederam neste ciclo de estudos. Destaquei, entretanto, apenas aquelas que me pareceram bem expressivas de uma tendência que marca a atual reforma penal brasileira. Não prosseguiremos nessa exemplificação porque desejamos dedicar o tópico final desta preleção a alguns aspectos do problema penal, isto é, a certos tópicos da reforma do direito penal.

6. Sobre a reforma penal, já tivemos a oportunidade de dizer que, presentemente, como em outras épocas, decorre ela de uma exigência histórica. Transformando-se a sociedade, mudam-se certas regras de comportamento. Isso é inevitável. E que a fisionomia da sociedade contemporânea não é a mesma daquela época para a qual se editaram as leis penais vigentes, é coisa que não deixa margem a dúvidas. A inteligência do homem contemporâneo pa- rece, cada vez mais, compreender que a sociedade humana não está implacavelmente dividida entre o bem e o mal, entre homens bons e maus - embora os haja. Mas sim parece estar predominantemente mesclada de pessoas que, por motivos vários, observam com maior ou menor fidelidade as regras estabelecidas por uma certa cultura, e de pessoas que, com maior ou menor freqüência, contrariam essas mesmas regras. Não há dúvida, porém, que tanto os primeiros como os últimos fazem parte, dentro de uma visão mais ampla, de um certo modo de ser e de viver prevalecente em determinada época, modo esse que talvez explique, senão todos, pelo menos um bom número de desvios de comportamento. Um importante teólogo, para justificar o fim não exclusivamente retribuitivo da pena, chega a fazer a seguinte afirmação: "Quase sempre a culpa do deliqüente é o resultado de uma forma conjunta de viver e das relaç̃̃es com o mundo que o rodeia; fracassos próprios e alheios se entrelaçam aí de marieira incrivel. Por isso não se pode evitar que o delinqüente, quando é castigado, faça também penitência e reparação pela culpa dos outros. Quando se tem em conta a obrigação da comunidade torna-se mais clara para se esforçar mais a mais pela reaceitação e reincorporação do delinqüente le da sua parte por uma reparação). Por isso a comunidade não tem apenas o direito de castigar, mas até o dever de realizar o castigo de tal maneira que não impeça uma ressocialização."

Se essa consideração estiver correta - e acreditamos que sim - a pena justa será somente a pena necessária e, não mais, dentro de um retributivismo kantiano superado, a pena-compensação do mal pelo mal, segundo o velho princípio do talião. Ora, o conceito de pena necessária envolve não só a questão do tipo de pena como o modo de sua execução. Assim, dentro de um rol de penas previstas, se uma certa pena apresentar-se como apta aos fins da prevenção e da preparação do infrator para o retorno ao convívio pacífico na comunidade de homens livres, não estará justificada a aplicação de outra pena mais grave, que resulte em maiores ônus para o condenado. O mesmo se diga em relação à execução da pena. Se o cumprimento da pena em regime de semiliberdade for suficiente para aqueles fins de prevenção e de reintegração social, o regime fechado será um exagero e um ônus injustificado. E assim por diante.

Contudo, como é fácil de perceber, para a aplicação desses novos princípios, será imprescindivel, em um direito penal democrático, apoiado no princípio da legalidade dos delitos e das penas, que a legislação penal reconstrua uma gama variada de penas criminais dispostas em escala crescente de gravidade, a fim de que o juiz, segundo certos critérios, 
possa escolher a pena justa para o crime e seu agente. Igualmente, as formas de execução da pena privativa da liberdade, quando esta tiver de ser aplicada, deverão desdobrar-se em etapas progressivas e regressivas, para ensejar maior ou menor intensidade na sua aplicação, bem como maior ou menor velocidade na caminhada do condenado rumo à liberdade. E assim terá que ser para cumprirem-se as diretrizes da individualização. Nenhuma pena terá, pois, um período rígido de segregação social. Os limites da sentença condenatória passam a ser limites máximos, não mais limites certos. A pena passa a ser, pois, uma pena programática

Por fim, a mais grave das penas - a privação da liberdade em regime fechado - deverá ser executada de modo adequado, enquanto durar, em celas individuais, assegurando-se ao condenado o trabalho interno remunerado, higiene, educação e outras formas de assistência.

Creio que os projetos de reforma penal e da lei de execução penal respondem a essas exigências, de modo cauteloso, dentro do possível e de uma certa realidade brasileira. Elaborou-se um rol de penas que vão desde a multa e a simples restrição de certos direitos até a privação da liberdade em regime fechado. Estabeleceu-se a escala de aplicação dessas penas, reservando-se as não privativas da liberdade para as infracões de menor importância, as privativas da liberdade para os crimes mais graves e para os delinqüentes perigosos ou que não se adaptem, por rebeldia, às outras modalidades de pena. Dentre as penas não privativas da liberdade, acolheu o Projeto as seguintes: multa, prestação de serviços à comunidade, interdicão temporária de direitos, limitação de fim de semana. Não vingou, entretanto, na comissão revisora, contra meu voto - digase de passagem - a multa reparatória do Anteprojeto de 1981, devido às sérias críticas apresentadas a essa inovacão

Penso, portanto, que nos projetos já encaminhados ao ministro Ibrahim Abi-Ackel, a pena criminal adquire, para o direito brasileiro, um novo sentido, ao qual estará indissoluvelmente ligada a mencionada exigência de 'necessidade de pena', ou de 'necessidade de uma certa pena', com as significativas conseqüências daí decorrentes.

\section{Mas não é só.}

7. Adotou-se, igualmente, sem as restrições e as reservas do passado, o princípio da culpabilidade. Assim, na reforma penal proposta, não se admitirá a aplicação de pena sem que se verifique a culpabilidade do agente por fato doloso ou pelo menos por fato culposo. E dessa tomada de posição, extraíram-se as devidas conseqüências: aboliu-se a medida de segurança para o imputável; diversifi- cou-se oftratamento dos paréádes, no concurso de pessoas; admitiu-sejerocusabilidade da falta de consciênch da ilicityer, sem contudo confundir a última com a a ignorantia legis; extirparam-se os vários resíduos de responsabilidade objetiva, principalmente nos crimes qualificados pelo resultado.

Com isso, conforme tivemos oportunidade de afirmar ${ }^{6}$, adotou-se um direito penal do fato-doagente que não descura o agente-do-fato, num esforço de compatibilização, nos limites do possivel, entre as teorias da culpabilidade pela condução de vida e da culpabilidade pelo fato singular, dando-se, não obstante, nítida prevalência à segunda corrente - ou seja, àquela que se traduz em um direito penal do fato.

O resultado dessa tomada de posição aponta em duas direç̃es, com importantes conseqüências.

A primeira delas revela a dupla função limitadora de principio da culpabilidade: uma com poder de despenalização, ou seja, excluindo de pena os fatos típicos não censuráveis ao agente; outra com renovado poder sobre a dosimetria da pena, estabelecendo que o limite máximo daquela não possa ultrapassar o grau de culpabilidade do agente. Julgamos desnecessário justificar o evidente significado prático da adoção desses princípios. Considere-se, porém, que, em um direito penal assim concebido, a aplicação da pena criminal restringir-se-á aos casos em que a exijam a necessidade de proteção da comunidade (prevenção) e a necessidade de preparação do infrator para uma razoável convivência pacífica no mundo social (ressocialização). ${ }^{7}$

A segunda direção, de maior importância, envolve-se com as três colunas de sustentação de um direito penal de índole democrática, a que nos referimos em nosso último livro, in verbis: "Na culpabilidade pelo fato... é o fato que dará os concretos e definitivos limites para a atuação do Estado na esfera penal. Franz von Liszt percebeu bem isso quando afirmava que, em sua opinião, por paradoxal que pudesse parecer, 'o código penal é a Magna Carta do delinqüente', protegendo não a coletividade, mas o indivíduo que contra ela se rebela, ao garantir-lhe o direito de ser castigado só quando ocorrerem os pressupostos legais e dentro dos limites legais. Ora, esses pressupostos e limites muito pouco valeriam se estivessem referidos a conceitos variáveis, pouco seguros, e não a características objetivas que só podem ser oferecidas pelo fato. Dai a já mencionada tipologia de fatos, não de autores. E aqui tocamos, com a lembrança da conhecida passagem de Von Liszt, o fundo da questão. O direito penal moderno está moldado segundo princípios liberais, elaborados, lenta e penosamente, através dos séculos. E, até hoje, não se conseguiu encontrar al- 
go melhor para substituí-los. Tentativas e experiências nesse sentido têm sido desastrosas. Dentro desse quadro, o nullum crimen nulla poena sine lege, o direito penal do fato e a culpabilidade do fato alinham-se imponentemente, numa perfeita seqüência e implicação lógicas, como colunas de sustentação de um sistema indissoluvelmente ligado ao direito penal de índole democrática. Por isso merecem ser preservados. Assim, apesar do crescimento dos índices de criminalidade e - o que é pior - do recrudescimento do crime atroz, violento, ao lado do aparecimento de novas formas delinqüenciais que se valem dos próprios instrumentos da técnica e do progresso, parece-nos que a procura de instrumental mais adequado de combate ao crime deve ser feita com muito engenho e arte, para não se pôr em risco o que já constitui valiosa conquista da humanidade".

8. Para concluir, duas palavras sobre as medidas de segurança, tema hoje bastante polêmico, diante das soluções contraditórias adotadas pela maioria dos estatutos penais vigentes, com a conhecida fórmula híbrida do duplo binário.

9. As medidas de segurança, introduzidas na lei penal brasileira pelo Código vigente, são consideradas 'medidas de prevenção e assistência' pela exposição de motivos do ministro Francisco Campos (item 33). A experiência brasileira, contudo, não se revelou muito feliz na aplicação de tais medidas. Levantamento feito nos estabelecimentos penais do estado de São Paulo, em 25 de agosto de 1981, encaminhado à comissão revisora pelo desembargador Italo Galli, em nome de comissão de desembargadores, revela os seguintes dados:

\section{Quadro A}

a - condenados cumprindo medida de segurança.................................... 240

b - condenados aguardando cumprimento de medida de segurança......................... 1.594

c - condenados a penas superiores a 30 anos 840

d - condenados a penas superiores a 30 anos, que já tinham cumprido mais de 15 anos .... 23

Entre os condenados referidos na letra a lem cumprimento de medida de segurançal, somente sete, portanto aproximadamente $3 \%$, tinham sido declarados portadores de periculosidade real; os restantes, em número de 233, aproximadamente $97 \%$, sofreram imposição de medida de segurança por periculosidade presumida. Entre os que aguardavam o momento oportuno para cumprimento da medida (não foram fornecidos dados completos nesse particular), predominava elevado índice dos que receberam a medida por periculosidade presumida.
Na grande maioria dos condenados que receberam medida de segurança, o crime imputado era de roubo e furto (arts. 157 e $\S \S$ e 155 e $\S \S)$, registrando-se número menor de homicídio e cifras inexpressivas em relação a outros delitos, tais como: estupro, estelionato, lesões corporais, entorpecentes, receptação, dano e seqüestro.

Na penitenciária do estado de São Paulo, que possuía o maior contingente de condenados aguardando cumprimento de medida de segurança, a situação era a seguinte, em 29 de junho de 1981:

\section{Quadro B}

Condenados com medida de segurança não cumprida:

- roubo (incluindo 80 casos de latrocínio) 370

- furto ................................. 28

- homicidio .............................. 49

- entorpecente ........................ 7

- estelionato ........................... 5

- estupro ............................. 2

- lesão corporal ......................... 1

- segurança nacional .................... 1

Total 463

Condenados a mais de 30 anos:

- roubo (incluindo 69 casos de latrocínio) 274

- furto ................................... 5

- homicídio ............................ 33

- entorpecente........................ -

- estelionato .......................... 2

- estupro ........................... -

- lesão corporal ........................ -

- segurança nacional .................. -

Total

Condenados a mais de 30 anos que, em 29 de junho de 1981, haviam cumprido mais de 15 anos de pena:

- roubo (incluindo 5 casos de latrocínio) 9

- homicidio

Total

Os condenados, em número de 240, que cumpriam efetivamente medida de segurança, no estado de São Paulo, assim se distribuíam:

\section{Quadro C}

Presidio de São Vicente

Periculosidade presumida

Periculosidade real

Penitenciária de P. Wenceslau

Periculosidade presumida

Periculosidade real ..........................

Casa de Custódia e Tratamento de Taubaté

Periculosidade presumida ................. 99

Periculosidade real ......................... 1 
Instituto de Reeducação de Tremembé

Periculosidade presumida

Periculosidade real

Instituto Penal Agrícola Dr. Javert de Andrade

Periculosidade presumida ................. 1

Periculosidade real.

Penitenciária Feminina da Capital

Periculosidade presumida .................. 0

Periculosidade real ......................... 2

Penitenciária de Pirajuí

Periculosidade presumida ................. 0

Periculosidade real .............................. 1

Total

10. Embora a prudência mande que não se extraiam conclusões apressadas e definitivas, é possível dizer-se que esses dados, pelo menos, não enfraquecem a orientação da comissão no sentido de extinguir-se a medida de segurança para os agentes imputáveis.

Com efeito, o quadro $A$ faz supor que um bom número de delinqüentes que, além da pena receberam imposição de medida de segurança, não necessitariam dessa última por já estarem condenados a mais de trinta anos de prisão, tempo mais que suficiente para qualquer trabalho de 'prevenção e assistência', perfeitamente realizável durante o cumprimento da pena. Ou pretender-se-á realizar a 'prevenção e assistência', neste caso, após a extinção da pena, isto é, na velhice ou post mortem?

$O$ quadro $B$ induz-nos a pensar que o roubo (incluido o latrocínio) comanda as hipóteses de imposição de medida de segurança, mas comanda igualmente as condenações apenas superiores a trinta anos. E isso é explicável diante do fato incontestável de que o ladrão que age com violência ou grave ameaça à pessoa, além de sujeito à pena elevada, é quase sempre reincidente, dificilmente fica no primeiro crime. Por outro lado, sugere o mesmo quadro $B$ que, com alguma ampliação na possibilidade de agravamento de pena para os crimes cometidos com violência ou grave ameaça à pesșoa, teria o legislador 'absorvido' na pena do sistema atual - dentro do que seria razoavelmente necessário para a pretendida 'assistência e prevenção' - quase todas as demais hipóteses de cumprimento efetivo de medida de segurança, ficando de fora o furto, o entorpecente e o estelionato. Como os crimes de tráfico de entorpecentes, assim como os cometidos contra a Segurança Nacional, são objeto de legislação especial, não revogada pela reforma, projetada (art. 12 do Projetol, sobrariam apenas o furto e o estelionato, os quais, evidentemente, não justificariam, por si sós, a acolhida no sistema de um corpo estranho, qual seja a medida de segurança para o agente culpável e já punido com pena de longa duração.

11. Excluiu-se, portanto, do sistema proposto pela reforma a medida de segurança para o imputável, fazendo-se com que a pena criminal absorvesse a função de 'prevenção e assistência' antes conferida à primeira. Para que isso fosse possivel, reformularam-se os institutos do crime continuado e do livramento condicional, além de estabeleceremse novas regras sobre unificação da pena. Por outro lado, deu-se maior maleabilidade à execução da pena, conforme salientamos anteriormente, de modo que o tempo de permanência no regime fechado possa ser alterado no curso do cumprimento da pena, segundo o mérito ou o demérito do condenado.

Com essas diretrizes, o Projeto de reforma penal brasileiro, longe de retornar a fórmulas clássicas, dá um passo adiante, com solução original e coerente para o sério problema do agente imputável que já se tenha revelado um delinqüente habitual ou por tendência, sem necessidade de recorrer-se a pena totalmente indeterminada ou a fórmula do duplo binário que, como se viu, não foi bem assimilada pela experiência brasileira. Por outro lado, os interesses da sociedade, da manutenção da paz social e da prevenção do crime são preservados com a possibilidade de aplicação de penas de longa duração para os delinqüentes que, na terminologia atual, seriam considerados 'perigosos'.

12. Dissemos, há pouco, que "a procura de instrumental mais adequado de combate ao crime deve ser feita com muito engenho e arte, para não se pôr em risco o que já constitui valiosa conquista da humanidade".

A intenção dos autores dos projetos de reforma foi essa, sem nenhuma dúvida. Se atuaram, ou não, com engenho e arte, dirão um dia os senhores, e de modo certamente implacável e inapelável.

\section{Notas}

1. Conferência proferida no Instituto dos Advogados Bra sileiros, Rio de Janeiro, em 18 de abril de 1983

2. RASGOS fundamentales del movimiento internacional de reforma del derecho penal. In: La reforma del derecho penal, Barcelona, Universidade Autonôma de Barcelona, 1980. p.9

3. VI CONGRESSO SOBRE PREVENCCÃO DO CRIME E TRATAMENTO DO DELINQÜENTE. Caracas, ONU, 1980. A/CONF. 87/7, 9/7. p.4

4. TOLEDO, Francisco de Assis. Prevencão do crime e tra tamento do delinqüente, Revista dos Tribunais, 544: 471.

5. GRÜNDEL, Johanes. Temas atuais de teologia moral. Pe trópolis, s.d. p. 232.

6. PERSPECTIVAS do direito penal brasileiro. In: Jornadas de estudo do Ministério Público, Anais... Porto Alegre, 1981. p. 194. 
7. ROXIN, Claus. Iniciación al derecho penal de hoy. SeviIha, Universidad de Sevilha, s.d. p. 48-9.
8. PRINCIPIOS básicos de direito penal, São Paulo, Saraiva, s.d. p.57-8 